\title{
ANÁLISE QUÍMICA DE PIGMENTO VERMELHO EM OSSO HUMANO
}

Luis Carlos Duarte Cavalcante e Maria Conceição Soares Meneses Lage*

Departamento de Química, Centro de Ciências da Natureza, Universidade Federal do Piauí, 64049-550 Teresina - PI, Brasil José Domingos Fabris

Departamento de Química, Instituto de Ciências Exatas, Universidade Federal de Minas Gerais, CP 702, 31270-901 Belo

Horizonte - MG, Brasil

Recebido em 4/6/07; aceito em 14/11/07; publicado na web em 21/7/08

CHEMICAL ANALYSIS OF RED PIGMENT IN HUMAN BONE. This work presents a chemical study of human bones painted red located at the Morro dos Ossos site, Piauí State, Brazil. The pigment was studied using X-ray diffraction (XRD), energy dispersive spectroscopy (EDS), scanning electron microscopy (SEM), complexation reactions with thiocyanate and UV-Vis absorption spectroscopy. The results confirmed the presence of ochre and that the pigment layer is essentially composed of a mixture of clay and hematite, $\alpha-\mathrm{Fe}_{2} \mathrm{O}_{3}$.

Keywords: iron; hematite; archaeology.

\section{INTRODUÇÃO}

Todo o território piauiense encontra-se marcado pela presença do homem pré-histórico, o que pode ser visualizado pelos milhares de sítios arqueológicos distribuídos em toda a extensão territorial do estado, sendo a maioria deles caracteristicamente de arte rupestre, ${ }^{1-11}$ embora também sejam encontrados sítios históricos, aldeias de agricultores ceramistas, ${ }^{12}$ oficinas líticas, sítios paleontológicos ${ }^{13-17}$ e com enterramentos. ${ }^{18-20}$

No ano de 2004 foi encontrado o sítio arqueológico denominado Morro dos Ossos, ${ }^{21,22}$ situado no município de São Miguel do Tapuio, região leste do Piauí, rica em remanescentes pré-históricos. Apesar do difícil acesso, este sítio foi apropriado pela população das áreas circunvizinhas que o utilizam como local de pagamento de promessas, onde colocam cruzes, acendem velas, depositam ex-votos e soltam fogos de artifícios, pois na superfície há material ósseo que foi pintado utilizando-se pigmento de cor vermelha, na mesma tonalidade que as pinturas realizadas na parede do abrigo.

Estudos com espectroscopia de absorção molecular UV-Visível descartaram a possibilidade do uso do urucum (Bixa orellana L.) como pigmento neste ritual funerário. ${ }^{21} \mathrm{O}$ corante extraído do pericarpo das sementes de urucum é chamado de anato, sendo uma mistura de pigmentos de coloração amarelo-alaranjada em conseqüência da presença de vários carotenóides, com predominância absoluta de um atípico, conhecido como bixina, que possui cadeia isoprênica de 24 carbonos, contendo um ácido carboxílico e um éster metílico nas extremidades. Esta substância representa $80 \%$ dos pigmentos da Bixa orellana L. $^{23}$

Dessa forma, o objetivo deste trabalho é apresentar os resultados das análises químicas realizadas no pigmento que recobre os ossos humanos do sítio arqueológico Morro dos Ossos. Visando elucidar a composição química do pigmento, utilizou-se difração de raios $\mathrm{X}$, espectroscopia de energia dispersiva, microscopia eletrônica de varredura, reação de complexação com tiocianato e espectroscopia de absorção molecular UV-visível.

*e-mail: meneses.lage@hotmail.com

\section{O sítio Morro dos Ossos e seu estado de conservação}

O sítio Morro dos Ossos é um pequeno abrigo sob rocha, localizado em alto de vertente, em cujo solo rochoso acham-se dispersas ossadas humanas pintadas em vermelho, pertencentes a vários indivíduos. Dentre os ossos observados verificou-se a presença de mandíbulas, fêmur, tíbias, patela e vértebras.

A parede do abrigo apresenta um painel pintado em vermelho com representações de segmentos paralelos de reta, pouco elaborados, sugerindo a utilização de ocre na forma de bastonete. A constituição arenítica do abrigo favorece o péssimo estado de conservação da parede com a presença de inúmeros depósitos de alteração e desplacamentos em diferentes espessuras. Ações antrópicas também têm contribuído para a depredação do sítio, especialmente pelo lixo deixado pelos peregrinos e prováveis ações vândalas de remoção de material arqueológico.

Apesar dos ossos estarem expostos ao ar livre, depositados diretamente no solo rochoso (Figura 1), sem a proteção de uma urna funerária, estão bem preservados, fato provavelmente devido ao clima extremamente seco da região e ao solo ácido, que não favorece a proliferação de microorganismos. Também não há evidência de nenhum tipo de marcas de agressão como cortes, perfurações ou fraturas nas ossadas. No entanto, não correspondem a esqueletos humanos completos, faltam alguns ossos, entre os quais os crânios, possivelmente em decorrência de vandalismo ou à presença de animais que porventura tenham estado no local.

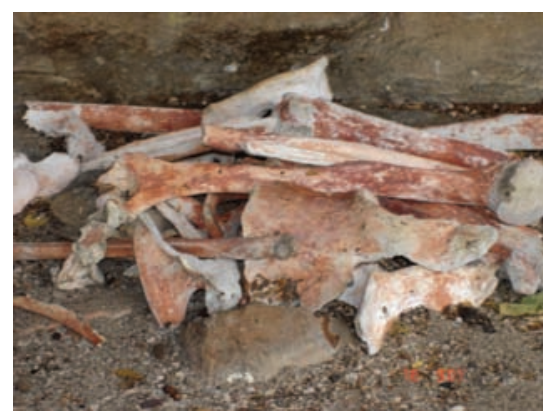

Figura 1. Material ósseo disperso na superficie 


\section{O uso de pigmentos naturais}

No Brasil, há referências de vários sítios onde foi comprovado o uso de pigmento em enterramentos pré-históricos, como na costa catarinense e em Pernambuco. Nesse estado convém mencionar os sítios Pedra do Alexandre, onde os ossos pintados em vermelho e cobertos de pigmento finamente peneirado pertenciam especialmente a crianças, e a Gruta do Padre, onde fragmentos de ocre foram encontrados junto à nuca e ao ventre de alguns esqueletos. ${ }^{24}$

Investigações mostram que os pigmentos minerais possuem numerosas propriedades. A partir de estudos etnográficos, tem-se conhecimento que o ocre é freqüentemente utilizado no tratamento de pele de animais, por preservar os tecidos orgânicos, protegendo-os da putrefação e de vermes, sendo usado também para a decoração de peles de animais. O pigmento vermelho pode ter sido aplicado em cadáveres, não apenas na crença sobre relação vidasangue, como é comumente acreditado, ou para restabelecer uma ilusão de saúde e vida em faces mortas, mas de preferência para neutralizar odores e ajudar a preservar o corpo. ${ }^{25}$

Ainda de acordo com Bahn, ${ }^{25}$ a prática dos povos pré-históricos de pintarem seus corpos pode em alguns casos ter sido puramente funcional, em vez de simbólica (como ocorre em ritos da puberdade feminina), ou estética. O ocre, por exemplo, seria muito efetivo em cauterização e limpezas de feridas, e ainda é usado pelos Barougas, da África do Sul, para secar ferimentos ainda sangrando.

Até o final do século XIX, o ocre era usado por médicos de lugarejos em muitas partes da Europa, como um anti-séptico no tratamento de ferimentos infectados.

Gilberto Freyre ${ }^{26}$ encontrou em suas prospecções relatos da pintura do corpo desempenhando entre os indígenas do Brasil função puramente mística, profilática contra espíritos maus, e, curiosamente, erótica, de atração ou exibição sexual. O urucum, segundo relatos do mesmo pesquisador ${ }^{26}$ protegia os selvagens (índios), durante a caça ou a pesca, da ação do sol sobre a pele, das picadas de mosquitos e de outros insetos e das oscilações de temperatura. Von den Steinen ${ }^{27}$ e Koch-Grünberg ${ }^{28}$ também citam o uso de pigmento vermelho em danças e cerimônias fúnebres.

\section{PARTE EXPERIMENTAL}

Um fragmento de osso coletado foi analisado no Departamento de Química da UFPI e posteriormente em laboratórios da UFMG.

Para identificar as fases cristalinas presentes, o pigmento raspado foi submetido à análise por difração de raios X (DRX), método do pó, utilizando um difratômetro Rigaku, modelo Geigerflex, com tubo de cobalto (Co K $\alpha$ ), tensão de $32,5 \mathrm{kV}$ e corrente de 25,0 $\mathrm{mA}$. A varredura foi feita no intervalo de 4 a $80^{\circ}(2 \theta)$ e a velocidade de varredura foi de $4^{\circ}(2 \theta) / \mathrm{min}$.

Foram obtidas algumas imagens por microscopia eletrônica de varredura (MEV), em equipamento Jeol, modelo JSM-840A, operando com tensão de $15 \mathrm{kV}$ e corrente de $60 \mathrm{pA}$. Previamente as amostras foram metalizadas com ouro.

A análise química qualitativa consistiu de ataque ácido com $\mathrm{HCl} 6 \mathrm{~mol} \mathrm{~L}^{-1}$ ao pigmento raspado da amostra e posterior acréscimo do agente complexante, $\mathrm{NH}_{4} \mathrm{SCN} 1 \mathrm{~mol} \mathrm{~L}^{-1}$, conforme Baccan e colaboradores. ${ }^{29} \mathrm{O}$ produto colorido da reação foi analisado por espectroscopia de absorção molecular UV-visível, utilizando-se um espectrofotômetro Hitachi de feixe duplo no tempo, modelo U3000 , com cubetas de quartzo de $1 \mathrm{~cm}$ de caminho óptico como recipientes para leitura das amostras.

Empregou-se também a técnica de espectroscopia de energia dispersiva (EDS) para fazer análises pontuais na amostra além da obtenção de mapas químicos dos elementos de interesse. Foi utilizado o equipamento Jeol, modelo JXA-8900RL, com energia de $15,0 \mathrm{keV}$, potencial de aceleração de $15,0 \mathrm{kV}$ e corrente de feixe de $12 \mathrm{nA}$. Previamente as amostras foram metalizadas com carbono.

\section{RESULTADOS E DISCUSSÃO}

A análise qualitativa com $\mathrm{NH}_{4} \mathrm{SCN}$ apresentou resultado positivo para ferro, sugerindo que o pigmento vermelho que recobre o osso humano é constituído de pigmento mineral. Na reação com o ferro, o complexo formado com o tiocianato apresenta uma coloração vermelha intensa. A Equação 1 representa o fenômeno reacional observado: $:^{29}$

$\mathrm{Fe}^{3+}+6 \mathrm{SCN}^{-} \rightleftharpoons \mathrm{Fe}(\mathrm{SCN})_{6}^{3-}$

Este é um teste altamente sensível para indicar a presença de $\mathrm{Fe}^{3+}$, não sofrendo interferência de outros cátions, incluindo $\mathrm{Fe}^{2+}$, e é feito em meio ácido para minimizar a hidrólise de $\mathrm{Fe}^{3+}$. $\mathrm{O}$ espectro eletrônico da espécie colorida é apresentado na Figura 2, mostrando a banda de absorção característica deste complexo de transferência de carga. ${ }^{30}$ Procedimento semelhante foi realizado com uma solução diluída de $\mathrm{Fe}\left(\mathrm{NO}_{3}\right)_{3}$, confirmando a feição espectral do complexo ferro-tiocianato e o máximo de absorção próximo de $480 \mathrm{~nm}$ (Figura 2).

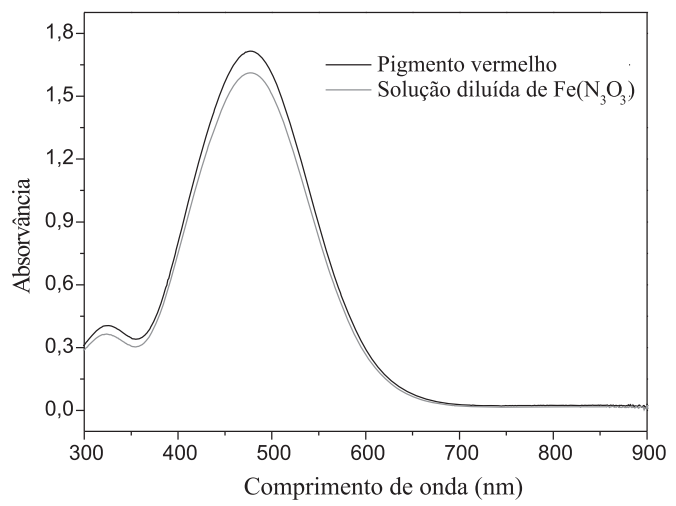

Figura 2. Espectro eletrônico do complexo colorido obtido da reação do pigmento com tiocianato em meio ácido e espectro da solução diluída de $\mathrm{Fe}\left(\mathrm{NO}_{3}\right)_{3}$, para comparação

$\mathrm{O}$ resultado da difração de raios $\mathrm{X}$ revelou apenas uma fase cristalina. $\mathrm{O}$ mineral identificado foi a hidroxiapatita, $\mathrm{Ca}_{10}$ $\left(\mathrm{PO}_{4}\right)_{6}(\mathrm{OH})_{2}$ (análise qualitativa feita por comparação com os dados da ficha JCPDS ${ }^{31}$ número 1-1008), que é o constituinte mineral do osso natural representando de 30 a $70 \%$ da massa dos ossos e dentes. ${ }^{32}$ A presença de material amorfo resultou em um background elevado e acredita-se que isso tenha camuflado os picos de cristalinidade característicos do mineral responsável pela cor vermelha (Figura 3).

O estudo da morfologia da amostra revelou a presença de ocre, evidenciando agregados radiais de hematita, Figura 4, com feições muito semelhantes àquelas relatadas por König, Pöllmann e Angélica. ${ }^{33}$ Os ocres contêm cromóforos de ferro e são os pigmentos minerais mais comumente encontrados na arqueologia. ${ }^{34-36}$ Verificou-se que as formas das partículas de hematita da amostra estudada são similares àquelas disponíveis na literatura. ${ }^{37-39}$

Os espectros EDS são ilustrados na Figura 5 e os mapas químicos são exibidos na Figura 6. A microanálise permitiu detectar os pontos de concentração do mineral responsável pela cor vermelha do pigmento presente no osso e isso pode ser acompanhado nos es- 


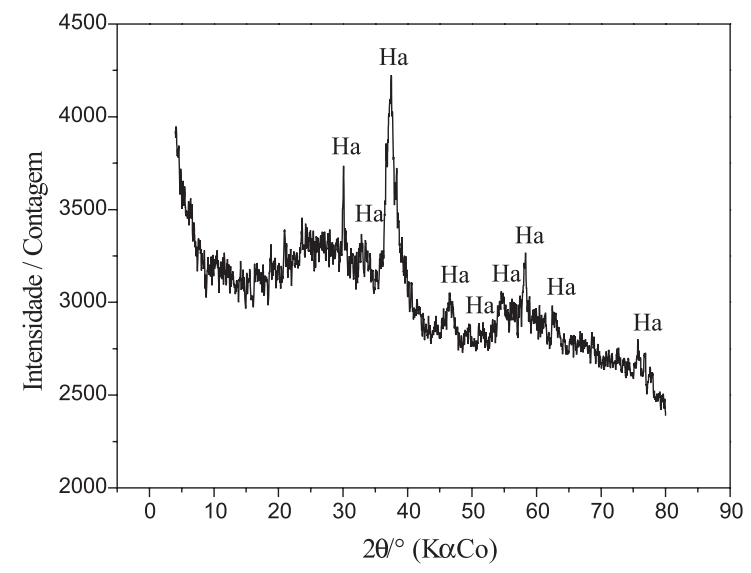

Figura 3. Difratograma de raios $X$ do pigmento raspado. $H a=$ hidroxiapatita

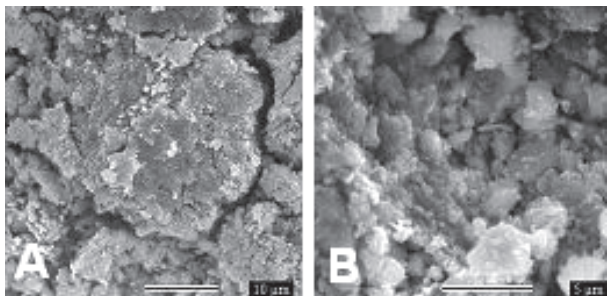

Figura 4. Micrografias de concentrações de pigmento. Aumentos de 2.000X(A) e $5.000 X(B)$

pectros EDS. Verificou-se que o espectro do osso puro apresentou os picos do $\mathrm{Ca}, \mathrm{P}$ e $\mathrm{O}$ (atribuídos à hidroxiapatita), não exibindo os picos do Fe (Figura 5A). Conforme a microssonda se aproximou de pontos com concentrações de pigmento, os sinais do Fe surgiram e se intensificaram com o aumento da matéria pigmentante. As Figuras $5 \mathrm{~B}$ a $5 \mathrm{D}$ ilustram os resultados deste procedimento de análise e ainda permitiram constatar a diminuição de intensidade dos picos de cálcio e fósforo, além da permanência do pico do oxigênio, sugerindo tratar-se de um óxido de ferro (Figura 5D). Associado ao surgimento dos sinais do Fe, verificou-se o aparecimento dos picos do $\mathrm{Al}$, Si e K, atribuídos a argilo-minerais constituintes da argila.

Os mapas químicos (Figura 6) apontam as concentrações de $\mathrm{Fe}$ e também permitem associar este metal ao elemento oxigênio, corroborando os dados dos espectros EDS. Da mesma forma que o cálcio, associado ao fósforo, corrobora os dados de difração de raios $\mathrm{X}$, os quais apontaram a presença da hidroxiapatita. Os demais picos observados nos espectros EDS (que, da mesma forma que o oxigênio, estão vinculados à presença do $\mathrm{Fe}$ ) foram atribuídos aos materiais amorfos que aparecem no mesmo difratograma supracitado.

\section{CONCLUSÃO}

Frente aos resultados obtidos pode-se concluir que não há dúvidas de que os ossos foram pintados com pigmentos à base de ferro. A complexação com o tiocianato evidenciou claramente a presença deste metal, porém a análise com difração de raios $\mathrm{X}$ não conseguiu evidenciar os reflexos do mineral responsável pela coloração presente no osso. A presença de material amorfo permitiu apenas a identificação da hidroxiapatita, como fase cristalina.

Os dados coligidos dos espectros EDS, bem como as micrografias e mapas químicos, indicam tratar-se de ocre, composto essencialmente de uma mistura de argila com hematita (fórmula ideal $\alpha$ $\mathrm{Fe}_{2} \mathrm{O}_{3}$ ).
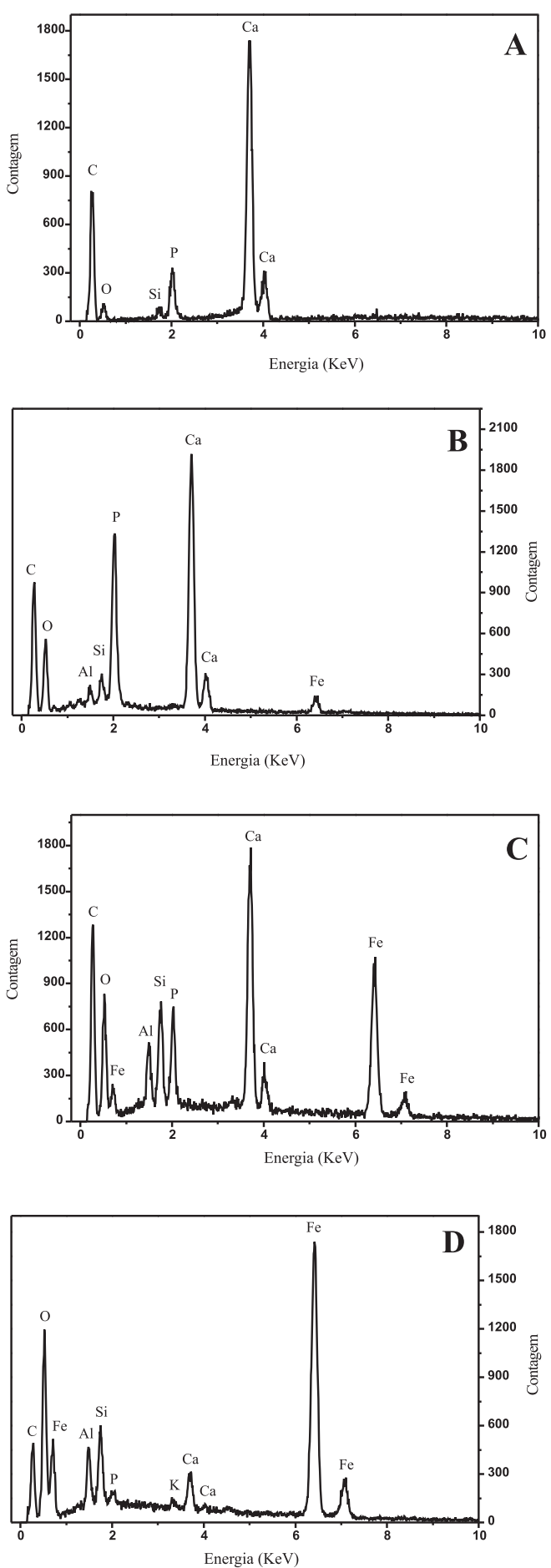

Figura 5. Espectros EDS. A: osso; B e C: osso com pigmento vermelho; D: pigmento vermelho
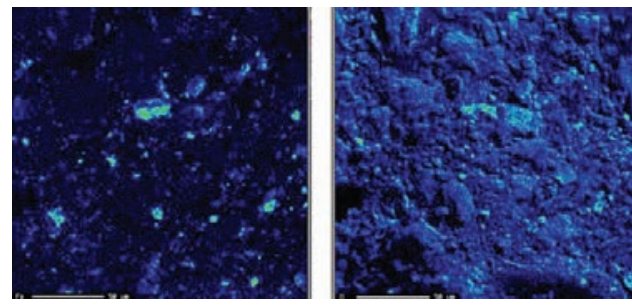

Figura 6. Mapas químicos para Fe e O, mostrando a distribuição destes elementos 


\section{MATERIAL SUPLEMENTAR}

Informações adicionais podem ser acessadas gratuitamente em http://quimicanova.sbq.org.br. Dentre os dados disponíveis em arquivo PDF encontra-se um mapa do Piauí com a localização do Município de São Miguel do Tapuio (Figura 1S), uma imagem geral do Sítio Morro dos Ossos (Figura 2S), bem como algumas micrografias da amostra obtidas por MEV (Figura 3S). Também estão presentes alguns mapas químicos que permitiram observar a associação que havia entre os elementos (Figura 4S).

\section{AGRADECIMENTOS}

Ao CNPq, pela concessão das bolsas, de Mestrado, a L. C. D. Cavalcante e de Produtividade em Pesquisa, a M. C. S. M. Lage e J. D. Fabris. Ao Depto. de Química da UFPI e aos laboratórios de Difração de Raios X e Microanálise da UFMG.

\section{REFERÊNCIAS}

1. Chiara, V.; Fumdhamentos 2007, 6, 1

2. Lage, M. C. S. M.; Cavalcante, L. C. D.; Gonçalves, A. S.; Fumdhamentos 2007, 6, 115.

3. Guidon, N.; Pessis, A.-M.; Parenti, F.; Guérin, C.; Peyre, E.; Santos, G. M.; Athena Review 2002, 3, 42.

4. Pessis, A.-M. Em Dating and the earliest known rock art; Strecker, M.; Bahn, P., eds.; Oxbow Books: Oxford, 1999, p. 41-47.

5. Lage, M. C. S. M. Em ref. 4, p. 49-52.

6. Lage, M. C. S. M.; Rev. Geologia 1996, 9, 83.

7. Lage, M. C. S. M.; Tese de Doutorado, Université Paris I, França, 1990

8. Guidon, N.; Delibrias, G.; Nature 1986, 321, 769.

9. Guidon, N.; Clio Arqueológica 1985, 7, 3.

10. Arnaud, M.-B.; Emperaire, L.; Guidon, N.; Pellerin, J.; L'Aire archéologique du sud-est du Piauí (Brésil), Éditions Recherche sur les Civilisations: Paris, 1984, v. 1: le milieu et les sites, "Synthèse" n. 16.

11. Guidon, N.; Andreatta, M. D.; Clio Arqueológica 1980, 3, 7.

12. Guidon, N.; Maranca, S.; Kestering, C.; Fumdhamentos 2007, 6, 92.
13. Guérin, C.; Faure, M.; C. R. Palevol 2004, 3, 35

14. Guérin, C.; Faure, M.; Geobios 2004, 37, 516.

15. Faure, M.; Guérin, C.; Parenti, F.; C. R. Acad. Sci. Paris 1999, 329, 443.

16. Guérin, C.; Faure, M.; Geobios 1999, 32, 629.

17. Guérin, C.; Curvello, M. A.; Faure, M.; Hugueney, M.; Mourer-Chauviré, C.; Fumdhamentos 1996, 1, 55.

18. Lessa, A.; Guidon, N.; A. J. Phys. Anthropol. 2002, 118, 99.

19. Peyre, E.; Guérin, C.; Guidon, N.; Coppens, Y.; C. R. Acad. Sci. Paris 1998 327, 335.

20. Peyre, E.; Fumdhamentos 1996, 1, 423.

21. Cavalcante, L. C. D.; Lage, M. C. S. M.; Nascimento, A. C. B. C.; Chiara, $\mathrm{V}$; Mneme Rev. Humanidades 2005, 18, 534.

22. IPHAN - Ministério da Cultura; Cadastramento e mapeamento de sítios arqueológicos do Piauí, $9^{\mathrm{a}}$ Etapa, 2004.

23. Da Costa, C. L. S.; Chaves, M. H.; Quim. Nova 2005, 28, 149.

24. Martin, G.; Pré-História do Nordeste do Brasil, Ed. Universitária da UFPE: Recife, 1996.

25. Bahn, P.; Prehistoric Art, Cambridge University Press: Cambridge, 1998.

26. Freyre, G.; Casa-Grande \& senzala, $34^{\mathrm{a}}$ ed., Record: Rio de Janeiro, 1998

27. Von den Steinen, K.; Unter den Naturvölkern Zentral-Brasiliens, Berlim, 1894.

28. Roch-Grünberg, T.; Zwei Jahre unter den Indianern, Stuttgart, 1908-1910.

29. Baccan, N.; Aleixo, L. M.; Stein, E.; Godinho, O. E. S.; Introdução à semimicroanálise qualitativa, $3^{\mathrm{a}}$ ed., Editora da Unicamp: Campinas, 1990.

30. Skoog, D. A.; West, D. M.; Holler, F. J.; Crouch, S. R.; Fundamentos de Química analítica, Pioneira Thomson Learning: São Paulo, 2006.

31. JCPDS - Joint Committee on Powder Diffraction Standards; Mineral Powder Diffraction Files Data Book, Swarthmore: Pennsylvania, 1980.

32. Mavropoulos, E.; Dissertação de Mestrado, Fundação Oswaldo Cruz, Brasil, 1999.

33. König, U.; Pöllmann, H.; Angélica, R. S.; Rev. Esc. Minas 2002, 55, 2.

34. Hall, K.; Meiklejohn, I.; Arocena, J.; Geomorphology 2007, 91, 132.

35. Marshall, L.-J. R.; Williams, J. R.; Almond, M. J.; Atkinson, S. D. M.; Cook, S. R.; Matthews, W.; Mortimore, J. L.; Spectrochim. Acta, Part A 2005, 61, 233

36. Mortimore, J. L.; Marshall, L.-J. R.; Almond, M. J.; Hollins, P.; Matthews, W.; Spectrochim. Acta, Part A 2004, 60, 1179.

37. Otake, T.; Wesolowski, D. J.; Anovitz, L. M.; Allard, L. F.; Ohmoto, H.; Earth Planet. Sci. Lett. 2007, 257, 60.

38. Pourghahramani, P.; Forssberg, E.; Int. J. Miner. Process. 2007, 82, 96

39. Espin, M. J.; Delgado, A. V.; Durán, J. D. G.; J. Colloid Interface Sci. 2005, $287,351$. 


\section{ANÁLISE QUÍMICA DE PIGMENTO VERMELHO EM OSSO HUMANO}

Luis Carlos Duarte Cavalcante e Maria Conceição Soares Meneses Lage*

Departamento de Química, Centro de Ciências da Natureza, Universidade Federal do Piauí, 64049-550 Teresina - PI, Brasil José Domingos Fabris

Departamento de Química, Instituto de Ciências Exatas, Universidade Federal de Minas Gerais, CP 702, 31270-901 Belo Horizonte - MG, Brasil

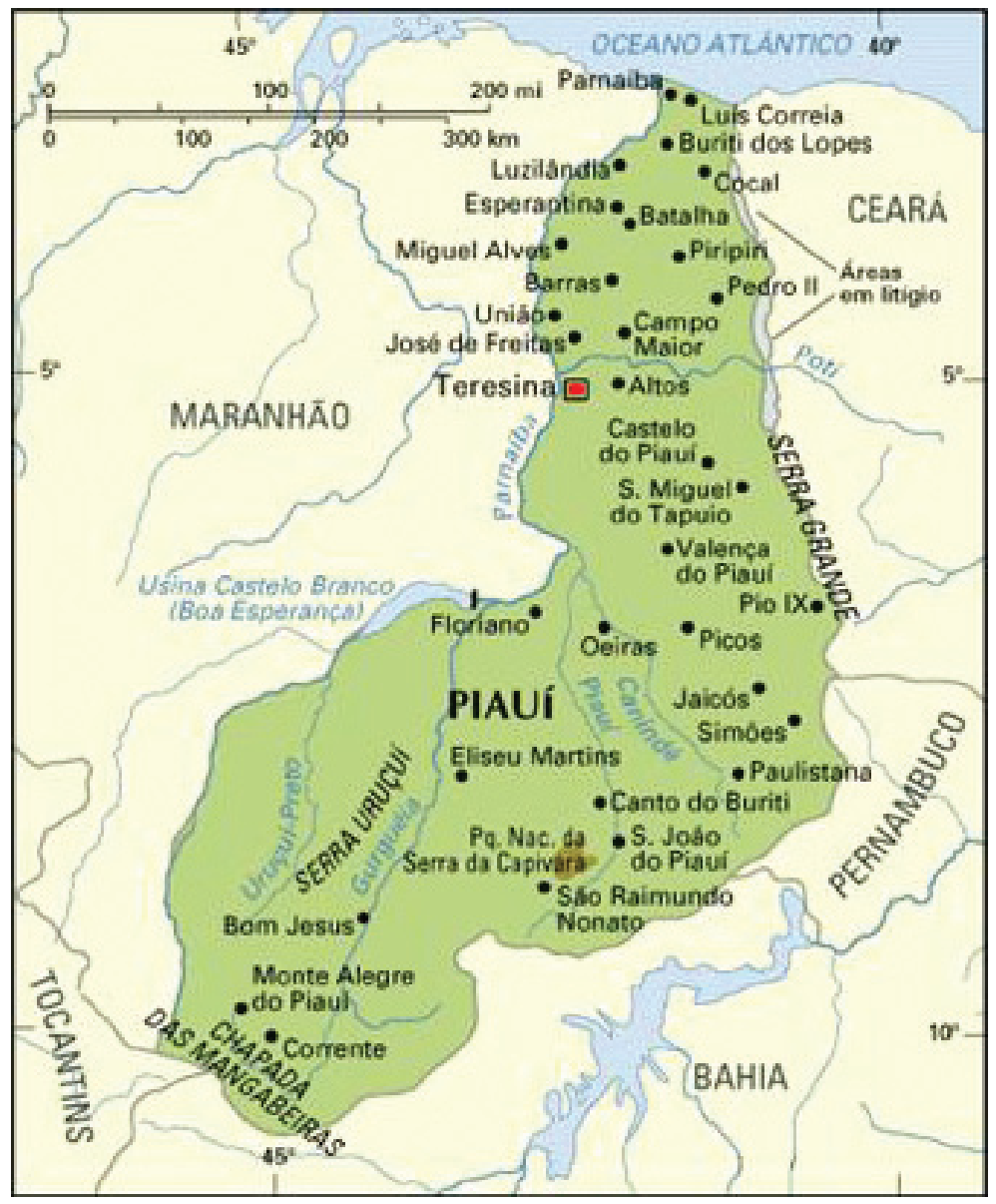

Figura 1S. Mapa do Piauí com a localização do Município de São Miguel do Tapuio

*e-mail:meneses.lage@ hotmail.com 


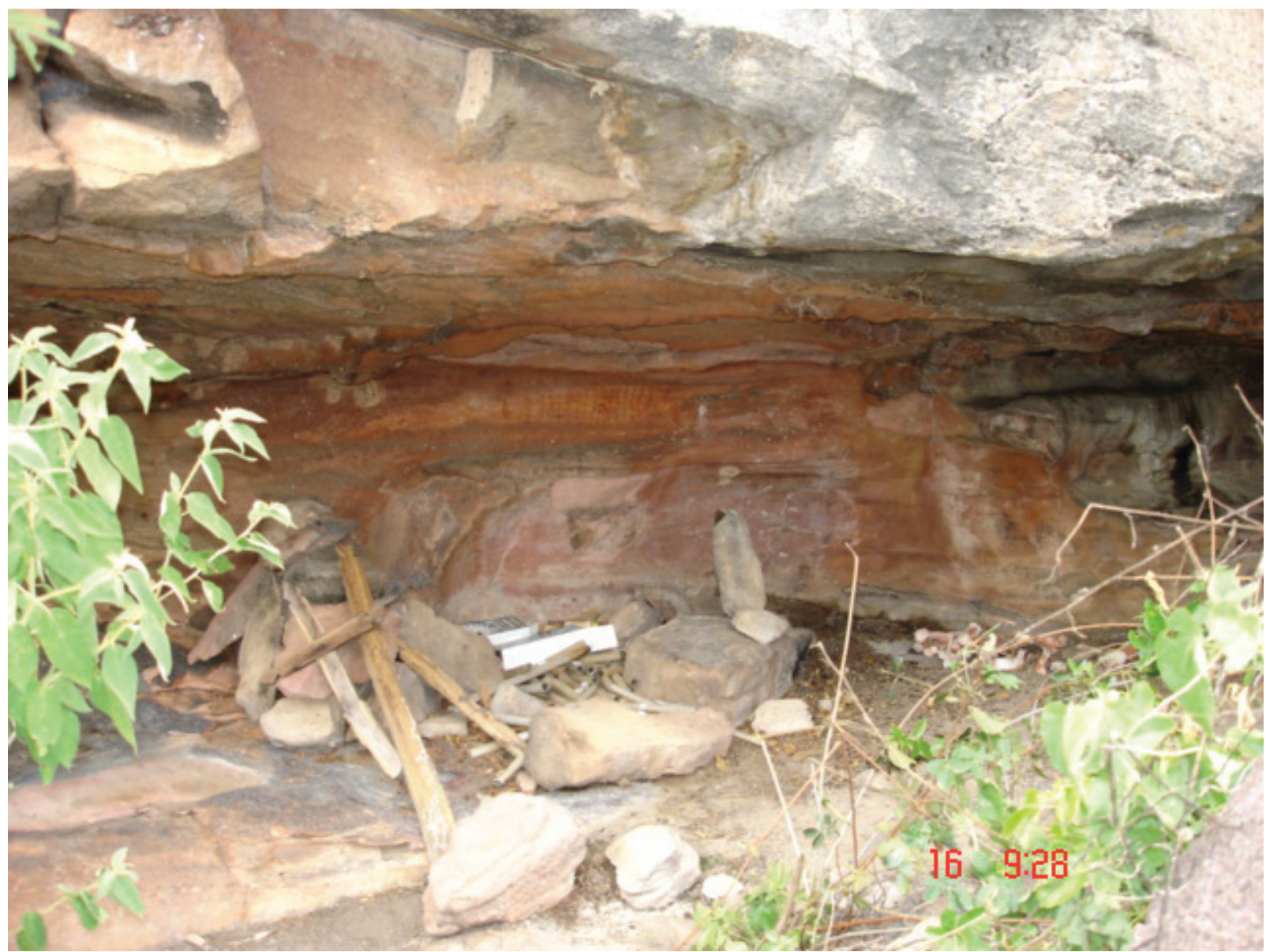

Figura 2S. Sítio Morro dos Ossos
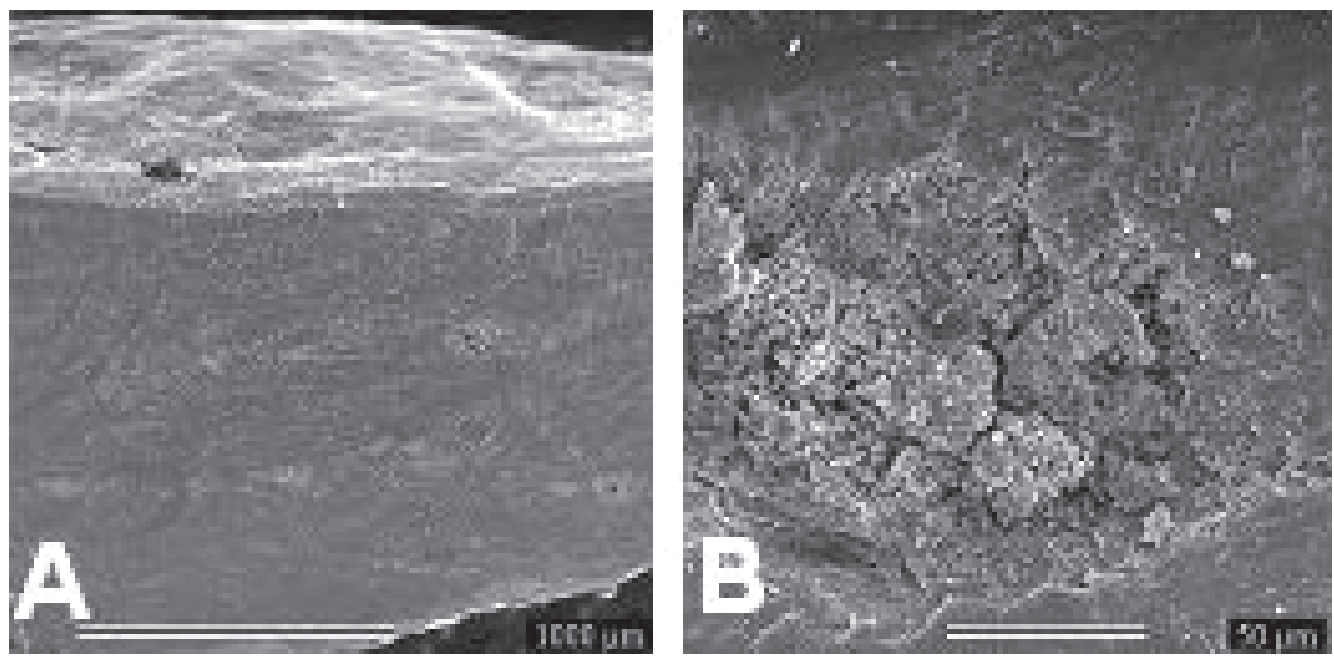

Figura 3S. Micrografias. A: fragmento de osso com resquícios de pigmento (aumento de 40X); B: concentração de pigmento (aumento de 500X) 

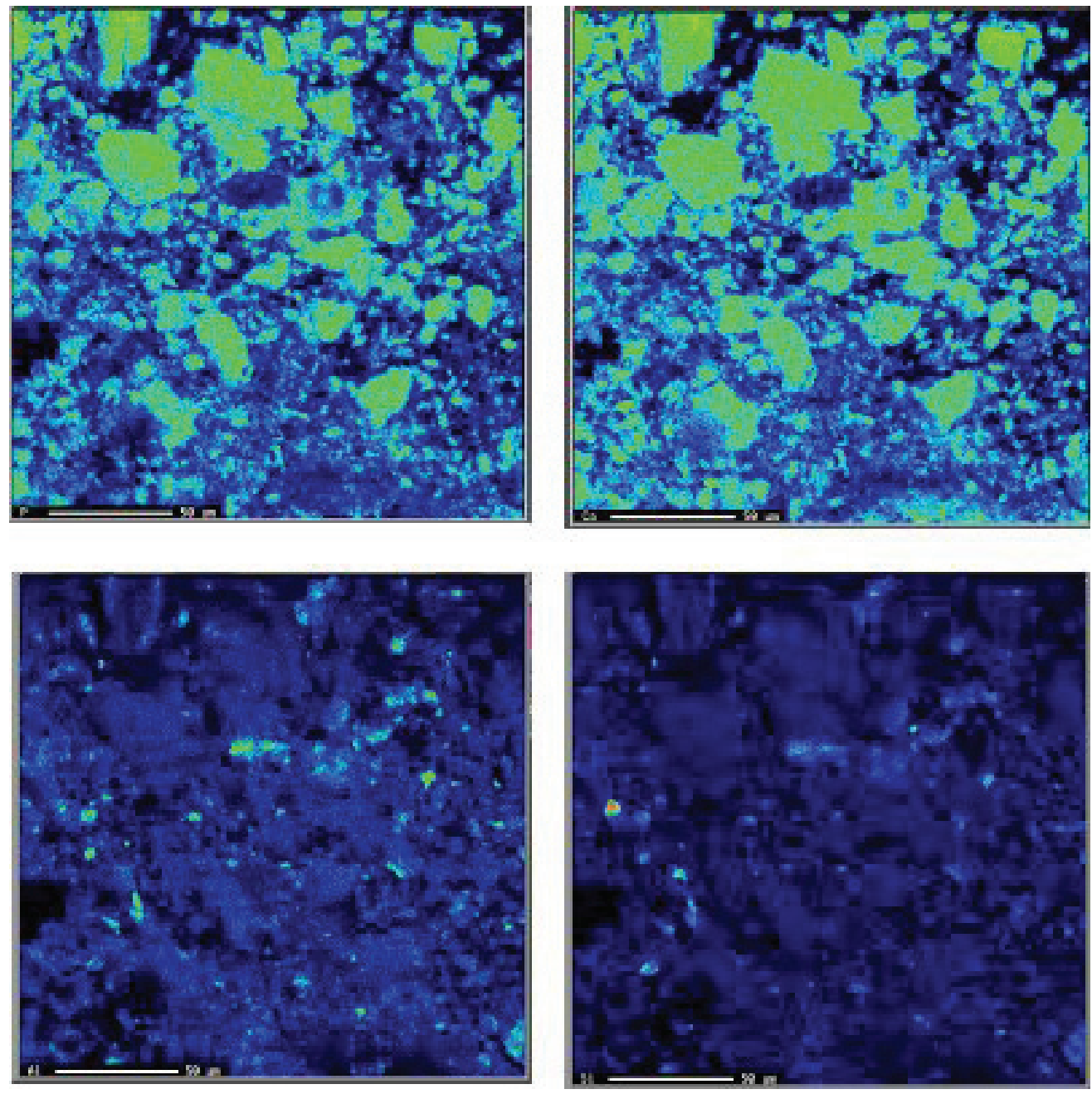

Figura 4S. Mapas químicos para Ca, $P$, Al e Si, mostrando a distribuição destes elementos 